\title{
Survey of the Existing Residential Buildings Stock in the UAE
}

\author{
Athari AlNaqbi, Wafa AlAwadhi, Abeer Manneh, Ayoub Kazim, and Bassam Abu-Hijleh
}

\begin{abstract}
This paper presents the results of a survey study that aims to establish a representative database of the existing residential building stock in the United Arab Emirates (UAE) starting in 1974 until 2012. The main goal is to identifying the approximate numbers built as well as applicable thermal energy insulation building regulations applicable at each period. It was found that buildings constructed pre-2003 did not have to adhere to any such regulations in both the emirates of Dubai and Sharjah. In Abu Dhabi, thermal insulation requirements were only introduce in 2011. At the time of writing this paper, there are no thermal insulation requirements in the other four emirates or the federal institutions. Energy modeling on a 1991 villa was done using the IES-VE energy modeling software. The results showed a $37.2 \%$ reduction in the total annual cooling load between the villa as built and if it had been upgraded to ESTIDAMA 1 Pearl thermal insulation requirements. This study clearly shows that there is great potential for reducing the energy consumption of existing buildings in the UAE.
\end{abstract} UAE.

Index Terms-Existing building stock, energy efficiency,

\section{INTRODUCTION}

There is an increasing determination in the UAE to reduce CO2 emissions as part of the global effort to reduce greenhouse gases and mitigate the effects of global warming. The focus until now has been on regulations for new buildings. As a young country, compulsory building regulations relating to energy savings and conservation were only introduced in the past decade (2003 in Dubai and 2007 in Abu Dhabi). This means that even if all new buildings were to adhere to significantly high energy conservation standards, the UAE would still have a large stock of buildings, some just completed, which have excessive cooling loads and thus are not environmentally friendly. This can be seen from the data that shows that the UAE has one of the highest electricity consumptions per capita in the world. This reflects negatively on the $\mathrm{CO} 2$ emissions as the UAE has the 2nd highest $\mathrm{CO} 2$ emissions per capita in the world. If the UAE is to significantly reduce its $\mathrm{CO} 2$ footprint, the energy inefficiencies in the existing building stock needs to be addressed.

This paper presents the results of a survey study that aims

Manuscript received September 12, 2012; revised October 17, 2012. This work was supported by the Emirates Foundation, ExxonMobil and GASCO under Grant 2011/157.

A. AlNaqbi, W. AlAwadhi, A. Manneh, and B. Abu-Hijleh are with The British University in Dubai, Dubai, UAE (e-mail: 90073@student.buid.ac.ae; 100138@student.buid.ac.ae; bassam.abuhijleh@buid.ac.ae)

A. Kazim is with Dubai Knowledge Village and Dubai International Academic City, Education Cluster, TECOM Investments, Dubai, UAE (ayoub.kazim@kv.ae). to establish a representative database of the existing building stock in the UAE identifying the approximate numbers built as well as building technologies and material used. Computer simulation is used to estimate the energy consumption of several existing buildings. The buildings are chosen in such a way that they are representative of the wide range of existing building stock in the UAE. The results show the high energy consumption in such buildings.

\section{LITERATURE REVIEW}

Although the Copenhagen conference has failed to reach a binding agreement on $\mathrm{CO} 2$ emission reductions, all participants have indicated that they have devised their own plans and targets for these reductions. The gravity of the problem is such that a binding agreement will surely follow soon. As of February 18 2010, 101 countries have, or are likely to engage with the accord, representing $81.2 \%$ of the global emissions [1]. The accord lays out the required reduction in CO2 emissions by the year 2020. The proposed solutions are not universal. Each country will have to look at its own sources of $\mathrm{CO} 2$ emissions and possible remedies depending on its climatic conditions, potential energy resources available and level of human and industrial development.

The built environment is responsible for approximately $40 \%$ of the total primary energy consumption [2]. Although most of the new regulations focus on new buildings to be constructed, these new buildings add around $0.5-2 \%$ to the total building stock, depending on the type and the regional economic conditions [3, 4]. There is a growing realization that this is not enough. Even if all new buildings have zero $\mathrm{CO} 2$ emissions, the older inefficient building stock will cause the CO2 emission levels to remain unacceptably high. The only practical way of reducing $\mathrm{CO} 2$ emissions in the short to medium term is by refurbishing the existing building stock [5]. The maturity of the technical knowledge of refurbishment practices, coupled with their relatively low costs, makes refurbishment a better choice for reducing $\mathrm{CO} 2$ emissions than using renewable energy resources to supply the high demand of inefficient buildings. It is easier to reduce the demand than to provide more renewable supplies of energy.

There have been many studies conducted, in different countries, on the potential and needs for refurbishment of existing buildings [4], [6-9]. The studies looked at the environmental, social and economic aspects of the refurbishment process. In all cases, the results strongly favored the refurbishment of older buildings. The extent of the refurbishment process is strongly dependent on the age of the building, original building technology and materials as 
well as the local climatic conditions and environmental regulations.

As a young country, the UAE has been late in implementing energy conservation regulations for buildings. It was not until 2003, that Dubai Municipality started enforcing Decree 66 which included energy saving requirements, mainly insulation and glazing. In Abu Dhabi, the Urban Planning Council (UPC) was established in 2007 and became responsible for preparing and enforcing building regulation including energy saving requirements. This means that the majority of the buildings in the UAE were constructed with little or no consideration to energy savings. This is especially true for buildings constructed by developers to be sold to end users. Thus initial cost savings were the dominate concern rather than long term energy operating costs savings. This means that the vast majority of these inefficient buildings will still be operational in 2020, the target year for the Copenhagen accord. Without proper refurbishment of these buildings, the drain on energy used in the building will remain high and would require significant investment in renewable energy resources if the UAE is to achieve the required $\mathrm{CO} 2$ emissions reduction goals set for 2020.

The poor energy saving construction approach used along with the harsh weather conditions in the UAE have resulted in the UAE being ranked in the top 10 countries in terms of electricity and heat usage per capita and the 2nd highest in terms of CO2 emissions per capita [10]. The high growth in electricity demand (25, 50 and 76 terrawatt hr/year in 1995, 2003 and 2007, respectively [10]), is also an indication that new buildings are not incorporating energy savings measures. The highest electrical load comes from HVAC equipment which accounts for an average of $40 \%$ of the total year around electrical load and up to $60 \%$ of the peak electrical load during the summer time [11].

A recent study showed that applying the new $2011 \mathrm{Abu}$ Dhabi ESTIDAMA PEARL rating system can result in significant energy reductions [12]. The PEARL rating system has five levels starting with the mandatory level of 1 pearl and goes up to 5 pearls. In this study a recently built villa that adhered to the 2003 Dubai Municipality (DM) insulation code, which is not as stringent as the ESTIDAMA system, was analyzed to estimate the energy savings potential if it was built according to the ESTIDAMA system. The results showed energy savings results of $10 \%$ and $26 \%$ compared to the as built design if the villa was designed to the ESTIDAMA 1 pearl and 2 pearls standards, respectively. If this is the level of savings that could be achieved on a newly built villa then the potential savings for older buildings is expected to be much higher.

The first step in assessing the potential energy savings in the existing building stock in the UAE to try and quantify the numbers and thermal construction of these buildings, involves collecting the relevant data across the UAE. This is not an easy task as the UAE is a federation of seven emirates, each responsible for its own building regulations. On top of that there is the federal building regulation which applies to federal buildings anywhere within the UAE. Thus,for a complete picture, data needs to be collected from eight different institutions each with a different data storage/archiving system, if any. Thus the study focuses on the emirates with highest concentration of population/buildings i.e. Abu Dhabi, Dubai, Sharjah, Ajman, and Ras Al Khaimah as well as the federal buildings. Less than $10 \%$ of the UAE population lives in the two emirates not included in the study, Fujairah and Umm Al-Quwain [13], with some of this data being included in the federal data that lists residential buildings by the Ministry of Public Works (MoPW). MoPW is responsible for building public housing for UAE nationals in the Northern Emirates (Sharjah, Ajman, Ras Al Khaimah, Fujairah and Umm Al-Quwain). The MoPW does not build public housing in Abu Dhabi and Dubai as this task is taken over by the local governments in these two emirates.

\section{RESULTS AND DISCUSSION}

The objectives of this research are two folds; first to identify the thermal insulation codes applicable across the UAE at different time frames; the second is to estimate the number/area of existing buildings constructed in different time frames, and thus the thermal insulation regulation applicable at the time. Once this data is available, estimates of energy saving in the existing buildings can be performed using the energy modeling of representative buildings. This part has not been done yet and hopefully will be presented in future publications once completed.

Identifying the different applicable thermal insulation regulations was the easy part; partly because, if they exist, they need to be properly documented. Secondly, and sadly, it was found that there has been a lack of such regulations for a long time. Theearliest such regulations appeared in 2003. Additionally, the 1985 Abu Dhabi building regulations mentioned the use of thermal insulation but did not specify any values that needed to be adhered to. Even until now, only Abu Dhabi, Dubai and Sharjah have such regulations. The rest of the emirates as well as the federal government do not have comprehensive thermal insulation requirements; although some encourage the use of thermal insulation features without specifying minimum values. Three thermal insulation guideline timeframes have been identified: pre-2003 (no insulation regulations anywhere within the UAE), 2003-2011 and post 2011. Table I shows the required $\mathrm{U}$ values for the last two timeframes for the emirates that did have such regulations.

The data in Table I convey a strong massage; all buildings in the UAE before 2003 did not have to satisfy any thermal insulation requirements, however, some had voluntarily installed varying levels of thermal insulation but this tended to be the exception rather than the rule. The good news is that most of the buildings constructed during the building boom in Dubai and Sharjah had to comply with a decent level of thermal insulation. The 2011 regulation introduced in Abu Dhabi was a significant achievement as it pushed the thermal insulation requirements well beyond those of Dubai and Sharjah. This was at a time when Dubai slightly improved its requirements and Sharjah continued to use the requirements introduced in 2003. 
TABLE I: THERMAL INSULATION REQUIREMENTS IN THE UAE AT DIFFERENT TIMEFRAMES

\begin{tabular}{|l|l|l|c|c|}
\hline \multirow{2}{*}{ Emirate } & \multirow{2}{*}{ Timeframe } & \multicolumn{4}{|c|}{ U-value (W/m $\left.{ }^{2} \mathrm{~K}\right)$} \\
\cline { 3 - 5 } & & Wall & Roof & ${\text { Glazing }\left(\mathrm{SHGC}^{*}\right)}^{*}$ \\
\hline \multirow{2}{*}{ Abu Dhabi } & $2003-2010$ & \multicolumn{3}{|c|}{ NA } \\
\cline { 2 - 5 } & $2011^{* *}-$ & 0.32 & 0.14 & $2.2(0.4)$ \\
\hline \multirow{3}{*}{ Shabai } & $2003-2010$ & 0.57 & 0.44 & $3.28(\mathrm{NA})$ \\
\cline { 2 - 5 } & $2011-$ & 0.57 & 0.3 & $2.1(0.25)$ \\
\hline \multirow{2}{*}{ Shah } & $2003-2010$ & 0.57 & 0.44 & $\begin{array}{c}3.18(0.43) \text { for w/w } \\
2.18(0.43) \text { for } \mathrm{w} / \mathrm{w}>40 \%\end{array}$ \\
\cline { 2 - 5 } & $2011-$ & \multicolumn{4}{|c}{ No change from the 2003 requirements } \\
\hline
\end{tabular}

Solar Heat Gain Coefficient

${ }^{* * *}$ Requirements for 1 Pearl (mandatory) rating

${ }^{* * * *}$ Window/Wall ratio

The other item that can be read from Table I is the lack of any thermal insulation requirements in the other 4 emirates as well as in all federal projects irrespective of the emirate they are in. This coupled with the late introduction of the thermal insulation codes in Abu Dhabi, Dubai and Sharjah make it clear that a significant portion of the UAE's existing building stock has inadequate thermal insulation and could potentially benefit significantly from energy driven refurbishment work, but to do so we need to know the numbers and construction characteristics of these buildings in order to be to assess the scope and potential benefits of refurbishing this existing stock. This is where the second part of this work comes into play.

Collecting data about the existing buildings in the UAE proved to be very difficult. Ideally we wanted to collect information on the numbers, area and thermal insulation details of all residential buildings constructed in the UAE. Even though there were no thermal insulation requirements before 2003, different construction practices were used in the 1970s, 1980s and 1990s. The changes in wall material and construction layers

do impact the wall thermal insulation value and thus the energy consumption characters of the building. Details of the prevailing construction practices at different time frames will be collected later for the second phase of this study.

The team faced great difficulties and challenges in collecting the relevant residential data. All residential data in each of the seven emirates' municipalities were not available in a digital format in the period before 2000. Thus the research team had to rely on secondary data available through other establishments, e.g. bureau of statics (again there is a federal and multiple local bureaus of statistics each covering some aspects of the data and mainly after the year 2000). Only the MoPW had an electronic record of buildings constructed throughout the UAE. The team also went through some of the archives at municipalities to get some information about the typical residential housing being built at different times. Government red tape and other unforeseen circumstances significantly hampered this effort. In addition, the data available from the local municipalities were in different formats and with different levels of detail.

Table II shows the new private, i.e. non-MoPW, residential areas added in Dubai and Sharjah over time. There are no MoPW construction projects in Dubai but there are some in Sharjah, this will be detailed later after talking about MoPW construction. The "Buildings" data includes all pure and mixed use residential buildings of all heights: i.e. low rise, medium rise and high rise. The results in Table II show that $27 \%$ of the villas and residential buildings in Dubai were constructed pre-2003, this means they did not have to comply with any insulation regulations. The situation in Sharjah is much better where $14 \%$ of the villas and $7 \%$ of the residential buildings were constructed pre-2003, that is before the introduction of thermal insulation regulations. This translates to $12.8 \%$ of all residential construction (villas and buildings) in Sharjah being constructed pre-2003. These numbers indicate that the potential for existing buildings thermal refurbishment is much higher in Dubai that it is in Sharjah.

As for Ajman, only the total private built up area was available (2,697,195 $\mathrm{m}^{2}$ in 2010). For Ras Al Khaimah, no private built up area data was available as all relevant documentation was lost due to a fire shortly before the start of this work.

TABLE II: AREA of NeW Privet RESIDENTIAL Units AdDED IN DUbAI AND SHARJAH

\begin{tabular}{|l|c|c|c|c|}
\hline & \multicolumn{3}{|c|}{ New privet residential area added in $\left(\mathrm{m}^{2}\right)$} \\
\hline & \multicolumn{2}{|c|}{ Dubai } & \multicolumn{2}{c|}{ Sharjah } \\
\hline Period & Villa & Buildings & Villa & Buildings \\
\hline $1980-1989$ & 779,438 & $1,987,383$ & 62,550 & 28,400 \\
\hline $1990-1999$ & $1,566,506$ & $5,705,821$ & $1,623,900$ & 319,541 \\
\hline 2000- 2002 & $2,924,036$ & $3,687,755$ & 324,450 & 236,049 \\
\hline Total Pre- 2003 & 5,269980 & $11,380,959$ & $2,010,900$ & 583,990 \\
\hline 2003- 2011 & $14,228,703$ & $30,839,414$ & $12,472,285$ & $7,834,573$ \\
\hline
\end{tabular}

In Abu Dhabi, the Abu Dhabi bureau of statistics had compiled information regarding the number of housing units added every 10 years; however, no information was available regarding the area . Table III shows the number of private (non-MoPW) residential homes/buildings added in Abu Dhabi during different intervals, up to 2005. This information was received directly from the Statistics Centre-Abu Dhabi (SCAD) in response to an e-mail request. Note that all of these numbers are pre-2011 which means the buildings were constructed without any thermal insulation regulation. This is in stark contrast to the cases of Dubai and Sharjah shown in Table II earlier.

TABLE III: NUMBER OF NEW RESIDENTIAL UNITS ADDED IN ABU DHABI

\begin{tabular}{|l|c|}
\hline Period & Number of new units added during period \\
\hline$-1975^{*}$ & 34647 \\
\hline $1976-1985$ & 63828 \\
\hline $1986-1995$ & 87838 \\
\hline $1996-2001$ & 65028 \\
\hline $2002-2005$ & 40004 \\
\hline
\end{tabular}

* All building in Abu Dhabi utpo 1975

Focusing only on the number of new homes/buildings in each period shown in Table III could be misleading. Starting in 2000, more high-rise residential buildings were being built compared to the low and medium rise buildings of earlier eras. In addition, more of the units constructed were of large area. Table IV shows the number of residential units completed in the Jan - March quarter of 2011 in Abu Dhabi [14]. Table IV shows that the largest units comprised more than $79 \%$ of the units constructed during this period. This shows the need to get at least an estimate of the average size of the residential units being built in different time frames. 
TABLE IV: NUMBER OF NEW RESIDENTIAL UNITS OF DIFFERENT SIZES ADDED IN ABU DHABI DURING THE MARCH QUARTER 2011 [14]

\begin{tabular}{|l|c|}
\hline Building area $\left(\mathrm{m}^{2}\right)$ & Number of completed residential units \\
\hline Less than 300 & 241 \\
\hline $300-599$ & 154 \\
\hline $600-899$ & 171 \\
\hline $900-1200$ & 174 \\
\hline More than 1200 & 2894 \\
\hline
\end{tabular}

Table $\mathrm{V}$ shows the number of residential buildings constructed by the MoPW at different time frames in the five emirates in which it builds in. The data in table $\mathrm{V}$ shows a drop in the number of public housing units being built every decade. This is due in part to that fact that more UAE nationasl are becoming wealthier and are choosing to build their own customized houses rather than rely on the MoPW pre-designed units. At the same time, the units being built by the MoPW are becoming larger in size. Table VI shows the number and total area of units built by the MoPW in Ras $\mathrm{Al}$ Khaimah in different time frames. We can see that the earlier units averaged just under $100 \mathrm{~m}^{2}$ in area then the average size grows steadily to reach $360 \mathrm{~m}^{2}$ in the $2000-2012$ period. This was the most detailed data that we could get during this study. We need to remind ourselves that to date (September 2012) there is no thermal insulation regulation for MoPW buildings which means that there is great potential for energy savings in all these buildings constructed until the current date.

TABLE V: NUMBER OF NEW RESIDENTIAL UNITS ADDED BY THE MOPW IN DIFFERENT EMIRATES AND TIME FRAMES

\begin{tabular}{|l|c|c|c|c|}
\hline & \multicolumn{4}{|c|}{ Period } \\
\hline Emirate & $\begin{array}{c}1974-1 \\
979\end{array}$ & $\begin{array}{c}1980- \\
1989\end{array}$ & $1990-1999$ & $2000-2009$ \\
\hline Sharjah & 539 & 777 & 876 & 103 \\
\hline Ras Al Khaimah & 1369 & 530 & 0 & 400 \\
\hline Ajman & 330 & 390 & 589 & 124 \\
\hline Umm Al-Quwain & 385 & 56 & 511 & 27 \\
\hline Fujairah & 1021 & 540 & 690 & 772 \\
\hline Total & 3644 & 2343 & 2666 & 1426 \\
\hline
\end{tabular}

TABle Vi: Total Number, Total Area and Average Area of MoPW RESIDENTIAL UNits AdDED IN RAs Al KHAIMAH AT DifFERENT Time FRAMES

\begin{tabular}{|c|c|c|c|}
\hline Period & $\begin{array}{c}\text { Total number of } \\
\text { units }\end{array}$ & $\begin{array}{c}\text { Total area of units } \\
\left(\mathrm{m}^{2}\right)\end{array}$ & $\begin{array}{c}\text { Average area } \\
\text { per unit }\left(\mathrm{m}^{2}\right)\end{array}$ \\
\hline $1974-1979$ & 1582 & 156654 & 99 \\
\hline $1980-1989$ & 369 & 49819 & 135 \\
\hline $1990-1999$ & 6014 & 1840451 & 306 \\
\hline $2000-2012$ & 759 & 273613 & 360 \\
\hline
\end{tabular}

Based on the preceding data it is clear that the potential for refurbishment of existing buildings does exist in all emirates in the UAE although to different extents. To get an initial idea about the potential savings that could be achieved, energy simulation analysis was conducted for an existing building. The building chosen was one of the villas constructed by the MoPW in 1991. The building modeling and energy simulation were performed using the Integrated Environmental Solutions - Virtual Environment (IES-VE) version 6.4. IES is considered to be one of the top commercial energy modeling softwares and has been used in multiple research publications - see reference [15] for more detailed description of the software and some of the published research that used it.

Fig. 1 shows the computer model of the villa that is used in this simulation. The total floor area of the villa is $366 \mathrm{~m}^{2}$. The energy simulation was conducted over a whole year and the focus was on the total cooling load per annum. The simulation was run for two thermal insulation configurations: the 'as built' configuration and one with the ESTIDAMA minimum thermal insulation requirements, i.e. 1 Pearl. Table VII shows the U values for the two configurations as well as the total annual cooling load for both configurations. The results show a $37.2 \%$ reduction in the annual cooling load which means significant reduction in the electricity bill of the villa. The effect of the improved thermal insulation in the case of 1 Pearl, is most significant in the summer months, as seen in Fig. 2 which shows the monthly cooling load for both configurations. This initial test gives an indication of the potential savings that could result from refurbishing existing buildings. A more accurate estimate of the energy savings across the UAE can be achieved once the data of the existing buildings has been defined. At which point several buildings of different configurations and time frames will be simulated in order to come up with a national estimate of the potential energy savings form refurbishing existing buildings in the UAE.

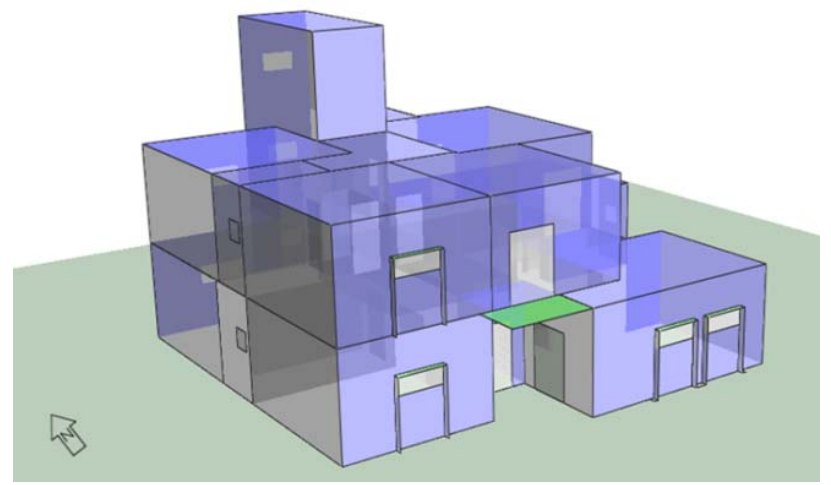

Fig. 1. Computer model of the villa used in the energy simulation.

TABLE VII: THE THERMAL INSULATION CHARACTERISTICS AND OVERALL ANNUAL COOLING LOAD OF THE TWO CONFIGURATIONS USED IN THE ENERGY SIMULATIONS TESTS

\begin{tabular}{|l|c|c|}
\hline \multicolumn{1}{|c|}{ ENERGY SIMULATIONS TESTS } \\
\hline & $\begin{array}{c}\text { As build } \\
\text { configuration }\end{array}$ & $\begin{array}{c}\text { ESTIDAMA 1 Pearl } \\
\text { configuration }\end{array}$ \\
\hline Wall U-value (W/m2 K) & 2.97 & 0.32 \\
\hline Roof U-value (W/m2 K) & 2.90 & 0.14 \\
\hline Glazing U-value (W/m2 K) & 5.57 & 2.2 \\
\hline Total annual cooling load (MWh) & 122.3 & 76.8 \\
\hline
\end{tabular}

\section{CONCLusions}

A survey of the existing buildings in the UAE has been conducted. This paper reports whatever data that could be collected toward this goal. The applicable thermal insulation guidelines at different timeframes are also reported. The task has been greatly hampered by lack of consistency between the different local regulations within the seven emirates and even federal regulations within the UAE. The data collected 
shows that around $27 \%$ and $12.8 \%$ of the residential housing (villas \& buildings) were built without having to adhere to any thermal insulation regulation in Dubai and Sharjah, respectively. All the data available for Abu Dhabi were pre 2011, the year in which the $1^{\text {st }}$ thermal insulation regulations were introduced in Abu Dhabi. As for the other four emirates as well as the federal institutions, no thermal insulation regulations exist as of yet. An initial energy modeling of an existing villa was conducted using the IES-VE energy modeling software. The effect of upgrading the existing design to the ESTIDAMA 1 Pearl requirements was also conducted. The results show a $37.2 \%$ reduction in the total annual cooling load of the villa studied. This gives a strong indication that thermal insulation refurbishment of existing buildings could result in significant energy savings.

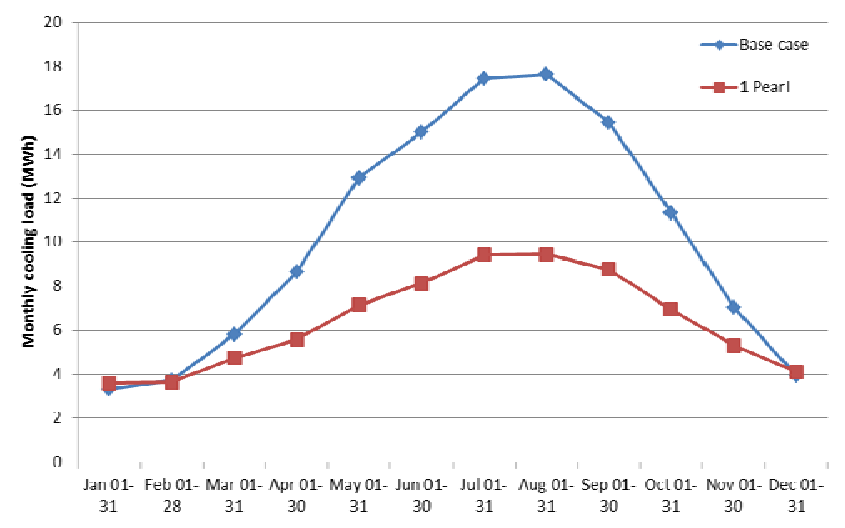

Fig. 2. Monthly cooling load of the two configuration used in the energy simulation study.

\section{REFERENCES}

[1] USCAN Climate Action Network. [Online]. Available: http://www.usclimatenetwork.org/policy/copenhagen-accord-commit ments (accessed on February 18, 2010).

[2] C. Petersdorff, T. Boermans, O. Stobbe, S. Joosen, W. Graus, E. Mikkers and J. Harnisch, Mitigation of $\mathrm{CO} 2$ Emissions from the Building Stock, Beyond the EU Directive on the Energy Performance of Buildings, ECOFYS, Cologne Germany, 2010.

[3] A. Peacock, P. F. Banfill, S. Turan, D. Jenkins, M. Ahadzi, G. Bowles, D. Kane, M. Newborough, P.C. Eames, H. Singh, T. Jackson and A. Berry, "Reducing CO2 emissions through refurbishment of non-domestic UK buildings," presented at the Improving Energy Efficiency in Commercial Buildings (IEECB) Conference, Frankfurt -Germany, 10 - 11 April 2008.

[4] C. Langston, F. Wong, E. Hui and L. Shen, "Strategic assessment of building adaptive reuse opportunities in Hong Kong," Building and Environment, vol. 43, pp 1709-1718, 2008.

[5] M. Sunikka and C. Boon, 'Environmental Policies and efforts in social housing: the Netherlands," Building Research \& Information, vol. 31, pp 1-12, 2003.

[6] A. Papadopoulos, T. Theodosiou and K. Karatzas, "Feasibility of energy saving renovation measures in urban buildings The impact of energy prices and the acceptable payback time criterion," Energy and Buildings, vol. 34, pp 455-466, 2002.

[7] A. Mickaityte, E. Zavadskas, A. Kaklauskas and L. Tupenaite, "The concept model of sustainable buildings refurbishment," Int. J. of Strategic Property Management, vol. 12, pp 53-68, 2008.

[8] S. Hong, J. Gilbertson, T. Oreszczyn, G. Green and I. Ridley, ”A field study of thermal comfort in low-income dwellings in England before and after energy efficient refurbishment," Building and Environment, vol. 44, pp 1228-1236, 2009.

[9] J. Ouyang, J. Ge. And K. Hokao, 'Economic analysis of energy-saving renovation measures for urban existing residential buildings in China based on thermal simulation and site investigation,” Energy Policy, vol. 37, pp 140-149, 2009.

[10] IEA CO2 Emissions From Fuel Combustion-Highlights, Paris-France, 2009.
[11] Dubai Electric and Water Authority site. [Online]. Available: http://www.dewa.gov.ae/community/conservation/ydc/savepower.asp x S. Chen, B. Mulgrew, and P. M. Grant, "A clustering technique for digital communications channel equalization using radial basis function networks," IEEE Trans. on Neural Networks, vol. 4, pp. 570-578, July 1993.

[12] G. S. Amin and B. Abu-Hijleh, 'Energy performance of a residential villa in Dubai designed in accordance with the Abu Dhabi PEARL Villa rating system," presented at the $1^{\text {st }}$ International Conference on Building Sustainability Assessment, Porto-Portugal, 23-25 May, 2012.

[13] UAE Bureau of Statistics. [Online]. Available: http://www.uaestatistics.gov.ae/ReportPDF/Population\%20Estimates \%202006\%20-\%202010.pdf, accessed September 2012

[14] Statistics Center - Abu Dhabi. (2011). Building Completion Statistics: March Quarter 2011. Abu Dhabi-UAE. [Online]. Available: http://www.scad.ae/SCAD\%20Publications/Building\%20Completion \%20Stat\%20English.pdf accessed September 2012.

[15] N. Al-Masri and B. Abu-Hijleh, "Courtyard Housing in Midrise Buildings - An Environmental Assessment in Hot-Arid Climate," Renewable \& Sustainable Energy Reviews, vol. 16, pp. 1892-1898, 2012.

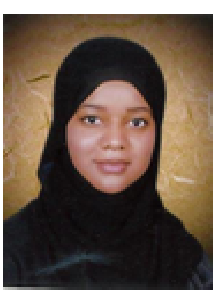

Athari AlNaqbi received her BSC in Civil Engineering from UAE University in 2000 and is currently an MSc candidate in the Sustainable Design of the Built Environment at the British University in Dubai.

She has more than 7 years of Civil Engineer experience in road infrastructure and urban planning projects

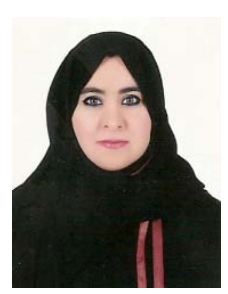

Wafa AlAwadi received her bachelor degree in electrical engineering in 2002 from the UAE University. She is expected to receive her master degree from the British University in Dubai in June 2013, specializing in the field of intelligent building design and automation.

She has been working as a Electrical Engineer at the Ministry of Public Works at her hometown branch since 2006. She has gained extensive experience in the field of electrical engineering having previously worked as Developer Electrical Engineer in Abu Dhabi Water and Electricity Authority (ADWEA) in one of ADWEA companies which is Abu Dhabi Distribution Company. She has undergone a 3-month training at Thomson-CSF Detexis Company in France.

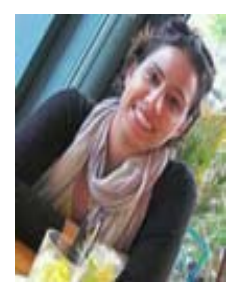

Abeer Manneh received her BSc in Architecture from Jordan University of Science \& Technology in 2008 and is currently an MSc candidate in the Sustainable Design of the Built Environment at the British University in Dubai..

Since 2008 she has been working as an Urban Designer on master planning projects in several Middle East and GCC countries.

Ms. Manneh is a certified LEED Accredited Professional and and a certified Estidama PCRS Pearl Qualified Professional. She is has also been a member of the Gaza Engineering Syndicate since 2008.

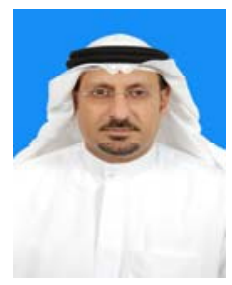

Ayoub Kazim holds a Bachelor's Degree in Mechanical Engineering from University of Alabama and a Master's Degree from the Polytechnic Institute of New York University. He received his Doctorate in Mechanical Engineering from University of Miami in 1998.

He is the Managing Director of the Education Cluster of TECOM Investments, a member of Dubai Holding. Dr. Kazim is in charge of both Dubai Knowledge Village (DKV) and Dubai International Academic City (DIAC). He is responsible for strategically steering all DIAC and DKV academic entities and further consolidating their statuses as leading centres of learning excellence in the region. Heading a proficient team of top-tier professionals across both campuses, Dr Kazim has successfully ensured consistent growth 
in the number of business partners at both DKV and DIAC. Under his guidance, Dubai Knowledge Village has channelled its focus on Human Resource Management, Consultation, Training and Personal Development programmes, as well as in positioning itself as a prominent events and conference centre for the region.

Dr. Kazim has over 20 years of experience gained from working in TECOM, Dubai Municipality and UAE University in Al Ain, He has an in-depth understanding of technical, administrative and academic work environments. This experience has led to his success in the education sector, in line with the vision of Dubai becoming a knowledge-based economy. In addition to his work with both DKV and DIAC, he is actively involved in research studies and has published numerous articles and technical papers on renewable energy, hydrogen energy, fuel cells, energy policy and economics.

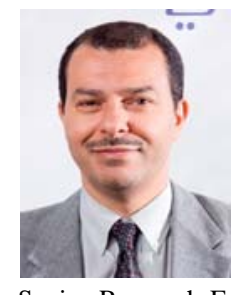

Bassam Abu-Hijleh hold a BSc, an MSc and a PhD in Mechanical Engineering, all from The Ohio State University. Hie has more than 20 years of post-PhD career include industrial, educational, research and administrative experiences.

He held several positions including Professor of Mechanical Engineering at Jordan University of Science \& Technology (Jordan), Visiting Research Professor at Swinburne University (Australia) and Senior Research Fellow at RMIT University (Australia). He has published more than 50 journal articles, in internationally renowned and refereed journals, and more than 30 international conference papers. He is also a reviewer for several well renowned international conferences and journals.

Prof. Abu-Hijleh's main research interests include Computational Fluid Dynamics (CFD), Simulation and optimization of heat transfer, Experimental and simulation study of solar energy, Renewable/alternative energy sources, advanced energy production practices and Energy conservation \& management. 